\title{
LUTA E MODERNIDADE POLÍTICA: SOBRE A CRÍTICA DE HEGEL À CONCEPÇÃO HOBBESIANA DE "ESTADO DE NATUREZA"
}

\author{
STRUGGLE AND POLITICAL MODERNITY: ON HEGEL'S CRITICS TO THE \\ HOBBESIAN CONCEPTION OF "STATE OF NATURE”
}

\author{
ERICK CALHEIROS DE LIMA
}

(UNB / Brasil)

\begin{abstract}
RESUMO
Seguindo a recente ressonância, tanto na teoria social quanto na filosofia política, de tópicos do pensamento hegeliano, pretendo aqui recuperar aspectos sócio-políticos que presidem a crítica de Hegel à filosofia política moderna. Primeiramente, tentarei mostrar que toda a crítica hegeliana ao contratualismo tem uma base sócio-teórica, a saber: a ideia, alcançada ainda em textos da juventude, de que a individualização - compreendida, quer em termos políticos quer em termos históricos, a partir do conceito de luta e de crime - tem uma base incontornavelmente societária (1). Em seguida, investigarei como se pode entender, a partir da discussão anterior, a assimilação crítica do conceito hobbesiano de "estado de natureza", o que conduzirá a uma apreciação dos diversos tratamentos dados por Hegel ao problema da luta (2).
\end{abstract}

Palavras-Chave: G.W.F. Hegel. Filosofia Política. Teoria Social. Filosofia do Direito. Teoria da Justiça.

\begin{abstract}
Hegel's social philosophy has obvious relevance to contemporary discussions on political philosophy and social theory concerning the social basis for the critique of political modernity. This paper supports the view according to which Hegel's critique of contract theory has a social theoretical framework, namely the view that processes of individualization, understood in political as much as in historical terms by the notions of struggle and crime, presupposes the dynamics of socialization (1). Then, I consider Hegel's critical assimilation of Hobbes's state of nature doctrine in order to provide a comparative discussion on Hegel's different treatments of struggle (2).
\end{abstract}

Key-Words: G.W.F Hegel. Political Philosophy. Social Theory. Philosophy of Right. Theory of Justice.

"A ideia mestra, que anima e estrutura a lógica e a metafísica de Hegel, é sua maneira de desenvolver, de acordo com o modelo de autoridade recíproca e responsabilidade cujo paradigma é o reconhecimento recíproco, o insight de Kant-Rousseau acerca do tipo fundamental de normatividade baseada na autonomia” (BRANDOM, 2002, 234).

\section{Introdução}

Para Hegel, reconhecimento é a base para a compreensão das normas sociais e da subjetividade autoconsciente (BRANDOM, 2002, 228 e ss.), bem como da constituição dos mundos-da-vida sócio-culturais (HABERMAS, 2004, 193 e ss.). A dimensão política do 
reconhecimento está no centro mesmo da noção de sujeito em Hegel: um sujeito não pode ser constituído sem ser reconhecido. Hegel inaugurou uma maneira de pensar que entende a Anerkennung - e a intersubjetividade - como constituinte de sujeitos, de identidades e de conhecimentos. O pós-estruturalismo procurou, por sua vez, substituir a diferença pensada em termos hegelianos por uma leitura de Nietzsche que entende que a diferença é sempre positiva e dispensa o trabalho da negatividade sobre os conceitos, que Hegel contava ser condição necessária para pensá-la. Neste sentido, sob a forte influência de Nietzsche, a noção de reconhecimento foi denunciada como uma variedade do império da "repetição", como embasamento convencional dos regimes de verdade enquanto regimes de exclusão da diferença.

\begin{abstract}
Não duvido, de modo algum, da influência saudável do pós-modernismo sobre os debates atuais. A crítica de uma razão que submete o todo da história a uma teleologia é tão convincente como a crítica à pretensão risível de preparar um fim para todas as alienações sociais. $O$ acento na fragmentação, na cisão e na marginalização, na alteridade, na diferença e no não idêntico, bem como o olhar sobre particularidades do local e dos indivíduos renovam motivos da primeira Teoria Crítica, sobretudo de Benjamin. Na medida em que reforçam a resistência contra as forças do universal abstrato e a uniformização, eles também retomam motivos de Hegel (HABERMAS, 2001, 186).
\end{abstract}

Frente a uma "teoria da socialização" proveniente de Nietzsche (HONNETH, 1989, caps. $4,5$ e 6$)^{1}$ - da qual parece decorrer, devido a "premissas questionáveis", um "certo gênero de idealismo linguístico", uma "crítica totalizante da razão" (HABERMAS, 2001, 186) e uma compreensão niveladora da modernidade (HABERMAS, 2004, 83) - há que se lembrar certamente de que a anteposição da luta ao ser-reconhecido (Anerkanntsein) inviabiliza a interpretação de Hegel como sustentando uma "intersubjetividade pressuposta", a qual poderia coincidir, no melhor dos casos, com aquilo que o "grande metafísico" chamaria de "universalidade abstrata". Ora, justamente deste inconveniente Hegel procura desvencilhar-se ao especificar a estrutura intersubjetiva do ser-reconhecido como resultado (HEGEL, 1970, 3, 12), como "universalidade concreta". De fato, poder-se-ia dizer, seguindo Honneth, que desconectar a universalidade concreta, própria à subjetividade descentrada pelo reconhecimento, do processo de seu devir como luta (Kampf) e crime (Verbrechen) é eclipsar totalmente sua utilidade para a crítica social de relações de poder e de não reconhecimento (Missachtung) de diferenças sob noções autocráticas da universalidade social. “Contudo, a justiça, a qual reconduz ao equilíbrio o universal preponderante sobre o singular, é, da mesma maneira, o espírito simples daquele que 
sofreu injustiça" (HEGEL, 1970, 3, 339), cita Honneth, como epígrafe de um livro recente (HONNETH, 2010). De outro modo, não se entende porque o reconhecimento é o desfecho que não aniquila, mas conserva e suspende

\footnotetext{
a enorme contradição de que [...] os dois Si que se referem aqui um ao outro constituem uma só identidade: por assim dizer, uma só luz; e, no entanto, são ao mesmo tempo dois que persistem em uma rigidez e aspereza completas, um em relação ao outro, cada um como algo refletido sobre si, absolutamente distinto do Outro e impenetrável por ele (HEGEL, 1970, 8, 218).
}

Neste encaminhamento teórico, o conceito de reconhecimento não somente é capaz de restaurar o envolvimento do conceito iluminista de crítica com a noção marxiana de luta, como também faz ressurgir, sob uma instigante ótica - e um tanto à revelia da acachapante crítica de Marx à noção de juridicidade, um vivo interesse pela conexão entre crítica da sociedade capitalista e uma filosofia contemporânea da justiça (LIMA, 2010). Na presente oportunidade, atendo-me ao âmbito restrito da filosofia política, eu gostaria de mostrar como se pode recuperar em Hegel a inspiração para a superação do quadro conceitual individualista do direito natural moderno, inadequada a uma plena compreensão da liberdade individual em sua necessária mediação intersubjetiva e em sua significação plenamente positiva. Aproximamo-nos, assim, do crucial tema da mediação entre as tradições aristotélica e kantiana (HONNETH, 2000).

\section{Filosofia Política como Teoria da Modernização: Luta, Individualização e Socialização nos textos de juventude}

Não me parece plausível questionar a tese de que o paradigma hegeliano da "luta por reconhecimento" tenha sido forjado pela combinação de três emblemas filosófico-políticos distintos, os quais podem também indicar as direções de seu possível aproveitamento em discussões contemporâneas (HONNETH, 1992, cap. 1): a tese aristotélica da anterioridade da pólis e a continuidade, que lhe é associada, entre as relações naturais e a comunidade política; ${ }^{2}$ o conceito hobbesiano de guerra, inserido como motivação antropológica da instituição contratual do estado; ${ }^{3}$ e a teoria fichteana da mediação intersubjetiva da consciência individual, que tem, como uma condição de possibilidade, o reconhecimento recíproco de direitos (LIMA, 2006, 128 e seg). Parece-me também lícito localizar esta combinação nos primeiros anos de Jena (1801/1802), período no qual Hegel, empreendendo críticas ao formalismo do contratualismo 
jusracionalista e ao subjetivismo da noção kantiana-fichtiana de autoconsciência (LIMA, 2006, 135 e seg), torna-se capaz de reconstruir, por um viés intersubjetivista, seu projeto de mediação entre o individualismo da filosofia prática moderna e o ideal clássico da anterioridade da pólis. ${ }^{4}$ Entretanto, é forçoso notar que, antes mesmo de efetuar esta criativa combinação de paradigmas, Hegel já aciona, em meio à tematização juvenil da totalidade ética, o conceito de luta, tornando-o interessante para um diagnóstico de época, isto é, para explicitar os desiderata de uma teoria social moderna, o significado político da modernidade e dos processos de modernização. ${ }^{5}$

\section{Socialização Originária no Espírito do Cristianismo}

Em Espírito do Cristianismo, Hegel lança mão do conceito de amor, fortemente marcado pelo ideário da Vereinigungsphilosophie (LIMA, 2006, 70 e ss.), prioritariamente para empreender uma crítica à moral deontológica (LIMA, 2011a). Entretanto, tal conceito tem, sem dúvida, um marcante e promissor desdobramento intersubjetivo. ${ }^{6}$ A tentativa de Jesus de retirar do "ama teu próximo" o caráter de mandamento revela que no amor os indivíduos não veem a individualidade diferente, mas antes que o "ser humano se reencontrou a si mesmo no outro" (HEGEL, 1970, 1, 394). Trata-se da transferência, para o terreno da intersubjetividade (HEGEL, 1970, 1, 363), da mesma cláusula de não dominação ${ }^{7}$ do universal sobre o particular, de maneira que, no registro sócio-político, o amor está

\footnotetext{
tão pouco abaixo de dever e direito que seu triunfo é muito mais não exercer domínio sobre nada e estar em face de outro sem um poder hostil. $\mathrm{O}$ amor venceu não significa algo como o dever venceu, ele subjugou o inimigo, mas antes ele superou a hostilidade (HEGEL, 1970, 1, 362/363).
}

$\mathrm{Na}$ verdade, de um ponto de vista político e teórico-social, Hegel pensa, no quadro desta sua crítica ao subjetivismo moderno, a relação entre o amor e a "individualização" como nexo explicativo da polarização sujeito-objeto ou a "lógica de objetivação de um sujeito" (HABERMAS, 2002, 44). Com efeito, por ser este "encontrar-se no outro", esta unificação com o outro, o amor é, por conseguinte, também cisão da unidade originária entre as duas individualidades. Hegel lança, assim, as bases de sua concepção jenense segundo a qual o processo da tomada de consciência de si mesmo e de autoafirmação, que origina o ser-para-si excludente, tem seu ponto de partida na unicidade da consciência (LIMA, 2006, 190). Ao 
conceber este processo como ruptura intersubjetiva da unidade da vida ética, Hegel estabelece as condições para apropriação crítica da noção fichtiana de reconhecimento: a condição transcendental da consciência de si apresenta um componente "contratualista", mas remete, por outro lado, à eticidade (SIEP, 1979, 46).

\section{Individualização como destino da modernidade}

Hegel aborda, pela primeira vez, o tema da "individualização através da socialização"8 na discussão sobre o amor enquanto reconciliação do crime, isto é, da pena como destino em contraposição à experiência "legalista" da justiça como pena. "Porque, a saber, as leis são somente unificações pensadas de contrapostos, então estes conceitos não esgotam, nem de longe, o caráter multifacetado da vida" (HEGEL, 1970, 1, 347). Em Espírito do Cristianismo, "crime""9 é uma ruptura das relações intersubjetivas primárias que possibilitam a perspectiva individual. Para além da tese enfática acerca de uma socialização prévia, Hegel confere, na sua investigação acerca do poder sócio-integrador do amor, significado filosófico aos processos formadores da modernidade política: o individualismo metodológico demanda uma teoria social de base holística.

A compreensão puramente "legalista" da pena é uma "reabsorção unilateral" do transgressor na comunidade, mesmo quando se passa da sanção à consciência da culpa.

\footnotetext{
E a pena somente executa sua dominação na medida em que a vida chegou à consciência, onde uma separação foi unificada no conceito. Contudo, sobre as relações da vida que não foram dissolvidas, sobre os lados da vida que são unificados e dados vivamente $[. .$.$] ela não exerce nenhuma violência (HEGEL, 1970, 1, 347).$
}

A pena é, para Hegel, enquanto contraposição do indivíduo infrator e do universal transgredido da lei, fixada no momento da identidade abstrata, ${ }^{10}$ expansão social da dominação pelo universal vazio da consciência. Assim como no embate intrassubjetivo entre universal e particular, também aqui Hegel argumenta que a identidade abstrata da unificação delito-pena deixa exterior a si o caráter variegado das relações vitais entre indivíduo e comunidade, notadamente os laços originários que estão por trás de "fenômenos" como o perdão e a reconciliação, responsáveis pela reestabilização do contexto valorativo compartilhado: a culpa pelo crime não é totalmente revogada na exterioridade da pena, permanecendo um lesão residual da vida ética, "um 
sentimento de impotência em face de um senhor com o qual o criminoso nada tem em comum e nada quer ter em comum" (HEGEL, 1970, 1, 345).

Em primeiro lugar, Hegel compreende a ação criminosa não como uma transgressão da lei, mas sim como violação da existência em comum, ruptura da vida ou da natureza própria (eigne Natur).

\begin{abstract}
O criminoso pretendia ter a ver apenas com vida estranha, mas ele destruiu apenas sua própria vida; pois vida não é diferente de vida, porque a vida está na divindade concorde (in der einigen Gottheit). Em sua petulância, ele em verdade destruiu, mas somente o caráter amistoso da vida (die Freundlichkeit des Lebens): ele a fez se tornar um inimigo (HEGEL, 1970, 1, 342).
\end{abstract}

Com efeito, o crime, reconduzido às relações vitais rompidas por ele, pode suscitar a percepção da pena como destino, isto é, como movimento criado pelo anseio da vida cindida de voltar a ser o que era. "No destino [...] o ser humano conhece sua própria vida, e seu suplicar ao mesmo não é um suplicar a um senhor, mas antes um retornar a si mesmo e um aproximar-se de si mesmo" (HEGEL, 1970, 1, 345).

Ora, se conflitos pressupõem um solo originário a partir do qual apenas podem surgir como tais, a pena sofrida pelo "criminoso" é, mais profundamente, o poder da reação da vida danificada pelo próprio ato. Com sua concepção da pena como destino, Hegel pretende justamente compreender o "fenômeno" do crime no horizonte do processo de autoestranhamento e autodiferenciação da vida que deságua na reconciliação da vida consigo mesma no amor. "A vida reencontrou a vida no amor. Entre pecado e sua remissão, tampouco entre pecado e pena, imiscui-se um estranho. A vida se cinde consigo mesma e se reunifica" (HEGEL, 1970, 1, 354). $\mathrm{O}$ estranhamento entre o universal punitivo e o transgressor é, numa perspectiva originária, ${ }^{11} \mathrm{o}$ autoestranhamento da vida, o processo mesmo de sua autodiferenciação. "O destino é [...] incorruptível e ilimitado, tal como a vida. Ele não conhece quaisquer relações dadas, quaisquer diversidades de pontos de vista, da situação, nenhuma circunscrição da virtude" (HEGEL, 1970, $1,347)$.

O destino propicia uma reconciliação do "criminoso" com a comunidade ao fazer com que o indivíduo sinta sua lesão da vida contra si mesmo, contra o outro e contra a própria vida.

$\mathrm{O}$ ato do criminoso não é, considerado desta maneira, nenhum fragmento. A ação que vem da vida, do todo, apresenta também o todo. O crime, que é a transgressão de uma 
lei, é somente um fragmento, pois fora dela [a transgressão E.C.L] está já a lei, a qual não pertence a ela. $\mathrm{O}$ crime, o qual provém da vida, expõe este todo, mas [o expõe] partido, e as partes hostis podem novamente integrar-se em um todo (HEGEL, 1970, 1, $345)$.

A condição "subjetiva" de possibilidade do retorno da vida a partir da cisão é a percepção pelo transgressor de seu ato como seu isolamento do todo vital, como destruição da unidade da vida, o que se fundamenta na sua defrontação com a vida que, através de seu próprio ato, se tornou hostil, isto é, com o destino; pois nesta consciência de si mesmo como inimigo, ${ }^{12}$ consciência da ruptura dos laços vivos com a comunidade, da totalidade que se tornou hostil, está já contida a ideia de um impulso ao restabelecimento da unidade.

\begin{abstract}
A justiça está apaziguada (befriedigt), pois o criminoso sentiu a mesma vida que ele lesou dentro de si enquanto lesada. Os aguilhões da consciência moral (Gewissen) se tornaram embotados, pois, a partir do ato, o mau espírito deles retrocedeu: não há nada hostil mais no homem (HEGEL, 1970, 1, 346).
\end{abstract}

Para Hegel, a "pena" se transforma em "consciência ética", isto é, na tomada de consciência pelo indivíduo da preexistência, do caráter originário dos vínculos éticos lesados por seus atos e, por conseguinte, do estado atualmente fragmentado dos mesmos. Apenas esta radicalização da "pena" como "consciência ética", o reconhecimento reflexivo pelo(s) indivíduo(s) de sua pertença originária a laços de reciprocidade e a um mundo constituído por expectativas mútuas de comportamento, apenas o reconhecimento do "crime" e da "individualização" como abstração da eticidade que a embasa, constitui a condição de possibilidade da Versöhnung, ou seja, da reparação, da reposição da intersubjetividade originária destruída pelo conflito.

O significado mais abrangente do problema da "causalidade do destino"13 reside, portanto, em que a "individualização" é pensada como realidade derivada, como acontecimento que pressupõe um todo ético marcado pela reciprocidade do reconhecimento e da satisfação dos interesses privados. Nestes termos, um ato individual que põe em xeque a integridade da vida ética, representa, na verdade, sua suspensão momentânea, seu autoestranhamento, a neutralização forçada de sua validade prévia e originária.

A dinâmica do destino resulta antes da perturbação das condições de simetria e das relações recíprocas de reconhecimento de um contexto de vida constituído intersubjetivamente, do qual uma parte se isolou, alienando de si todas as outras partes da vida em comum (HABERMAS, 2002, 43). 
A equação, estabelecida por Hegel em Espírito do Cristianismo e seu Destino, entre a luta como processo de "individualização" e a causalidade do destino como percepção de uma "socialização originária" bem que poderia ser tomada enquanto componente filosófico-político de uma incipiente e profícua teoria da modernização. ${ }^{14}$

\begin{abstract}
A "reflexão" abandonada a si mesma deixa as totalidades orgânicas desunidas ruírem nas suas partes isoladas. Ela desfaz as relações intersubjetivas transformando-as em consequências da ação, observada reciprocamente, de atores que decidem conforme fins racionais, de tal modo que os indivíduos isolados são cortados das raízes das suas procedências comuns (HABERMAS, 2001, 174).
\end{abstract}

\title{
Totalidade Ética e Luta por Direitos
}

A relação entre socialização e individualização constitui o registro no qual Hegel tematiza, pela primeira vez, o conceito de "luta" (Kampf), vinculando-o à formação da autoconsciência individual pela mediação de reivindicações jurídicas. "Onde vida foi danificada, mesmo que tenha acontecido também ainda de modo tão jurídico (rechtlich) [...] aí entra em cena o destino..." (HEGEL, 1970, 1, 347) Hegel promoverá, então, uma apreciação positiva da negatividade intrínseca à ruptura da unidade.

A tese da socialização originária conduz à compreensão da totalidade ética como horizonte valorativo compartilhado, como mundo da vida forjado por uma rede de relações intersubjetivas de segurança e satisfação recíproca de interesses. Hegel sempre entendeu o específico da modernidade sob o signo do "Recht der Besonderheit des Subjekts" (HEGEL, 1970, 7,232 ), tanto que a marca indelével e constituinte de sua compreensão do moderno "Estado Ético" é a "liberdade concreta", o "deixar o princípio da subjetividade se consumar até o extremo subsistente por si da particularidade pessoal e, ao mesmo tempo, de reconduzi-lo à unidade substancial, e, assim, de manter essa unidade substancial nesse próprio princípio da subjetividade." (HEGEL, 1970, 7, 406). É lícito pensar, então, que Hegel parece contar com a ideia de que uma "individualização" potencialmente aberta e ilimitada corresponda aos resultados da modernização das sociedades ocidentais, calcada em "padrões de socialização e processos de formação que fomentam o desenvolvimento moral e o desenvolvimento do eu de jovens e impulsionam os processos de individualização para além dos limites de uma identidade convencional, de uma identidade que se atém a determinados papéis sociais" (HABERMAS, 
1991, 89). Esta “individualização", tornada uma necessidade histórica sob a modernidade, demanda de Hegel a tematização da relação entre vida e direito. A relação intersubjetiva sob a égide do paradigma da justiça é uma relação mutuamente excludente entre os indivíduos, cujo fim é estabelecer o ponto de vista reciprocamente reconhecido da igualdade do direito de ambos. “A retaliação e a igualdade da mesma é o princípio sagrado de toda justiça, o princípio sobre o qual deve repousar a constituição do estado" (HEGEL, 1970, 1, 331). O ponto de vista jurídicomoral da justiça define a formação e solidificação da esfera da igualdade dos direitos.

Mas a "positividade" intrínseca é também decorrência da imbricação entre socialização e individualização. Por incluir formação da igualdade, a justiça corresponde, enquanto processo geral da separação e mútua exclusão das individualidades (potencialmente de luta), também à possibilidade da desigualdade e da imposição unilateral de reivindicações. E, de fato, Hegel compreende o processo de formação desta esfera de mútua exclusão e igualdade como contendo o potencial para uma luta por direitos (Kampf für Rechte), a qual corresponde a uma ruptura da vida e da natureza que permanece incontornável com a manutenção deste ponto de vista: “é já a luta por direitos um estado não natural [...] no qual há contradição entre o conceito do direito e sua efetividade" (HEGEL, 1970, 1, 348). A formação do ponto de vista jurídico-moral encerra em si uma contradição de que a universalidade pensada individualmente no "conceito de direito", enquanto fundamento legítimo para ações, não se coaduna com a efetividade da garantia unilateral, que gera a luta.

\footnotetext{
Através da autodefesa do injuriado o agressor é, da mesma maneira, atacado e, por meio disso, posto no direito de autodefesa, de tal forma que ambos têm direito, ambos se encontram em guerra, a qual confere a ambos o direito de se defender (HEGEL, 1970, 1, $348 / 349)$.
}

A defesa do injuriado investe o agressor, na lógica do ponto de vista jurídico, do direito de se defender diante da investida que foi a reação do agredido. Assim, o conflito jurídico se torna apenas uma contraposição inexorável entre dois direitos, duas pretensões de universalidade: "na luta por direitos reside uma contradição. O direito, que é um pensado, portanto, um universal, [e] é, no agressor, outro pensado: assim haveria aqui dois universais, os quais se suspenderiam, mas, mesmo sim, são" (HEGEL, 1970, 1, 348).

Portanto, apenas com uma base fortemente valorativa e comunitária o ponto de vista da justiça poderia superar sua contradição. Por outro lado, sem esta base o risco de conflito é 
intrínseco à absolutização deste ponto de vista. A contradição entre conceito e efetividade do direito deságua na ruptura da unidade vital que é a "luta de vida contra vida" (HEGEL, 1970, 1, 348). Para Hegel, a solução pela delegação do poder decisório a uma instância competente, compatível com o princípio da igualdade que rege o ponto de vista jurídico-moral da justiça (HEGEL, 1970, 1, 348/349), não restauraria a unicidade vital das consciências.

\section{Luta e Eticidade no System der Sittlichkeit}

No System der Sittlichkeit, através da Auseinandersetzung com a teoria fichtiana da mediação intersubjetiva da consciência, ${ }^{15}$ criam-se as condições para a conexão entre o modelo hobbesiano da luta com a tese aristotélica da anterioridade da pólis (LIMA, 2006, 62-64/114 e ss.). O crime surge da possibilidade de um uso "destrutivo", ${ }^{16}$ por parte dos singulares, da liberdade negativa que, na organização jurídica da eticidade relativa, é-lhes atribuída enquanto pessoas de direito. Hegel empreende, então, uma "tipologia" das formas de autoexclusão, a qual conduz progressivamente, segundo Hegel, à eticidade absoluta ${ }^{17}$.

O ápice da atitude autoexcludente é a exasperação do conflito aberto pelo desrespeito ao direito da pessoa, porque a atitude de autoexclusão do criminoso é de tal forma levada às últimas consequências que ele próprio já se dirige à lesão não de uma determinidade singular, mas sim à integridade do atingido.

\footnotetext{
Porque a negação somente pode ser uma determinidade, então esta - que o todo esteja em jogo - tem de ser elevada a um todo. Mas por meio disso, que ela é pessoal, ela é imediatamente o todo; pois a determinidade pertence à pessoa, a qual é a indiferença do todo (HEGEL, 2002, 41).
}

Neste quadro da lesão pessoal, em que a própria vida é, na forma da integridade da existência de uma pessoa, vituperada, há, segundo Hegel, uma lesão da honra: "porque [...] a esta indiferença se contrapõe a abstração da particularidade lesada, então através da última também aquela é posta idealmente, e o lesado é a honra” (HEGEL, 2002, 42).

\footnotetext{
"Honra" é a atitude que eu tomo frente a mim mesmo, quando eu me identifico positivamente com todas as minhas propriedades e peculiaridades [...] por "Honra" é designada, portanto, uma autorrelação afirmativa, a qual está vinculada estruturalmente à pressuposição do reconhecimento recíproco da particularidade individual de cada um (HONNETH, 1992, 41).
} 
Neste contexto, a luta entre dois singulares (Zweikampf) surge como risco indiferente a ambos os lados (HEGEL, 2002, 43). "Através da honra o singular se torna um todo e pessoal, e a negação aparente dos singulares somente é a lesão do todo, e assim emerge a luta da pessoa como um todo contra a pessoa como um todo (der Kampf der ganzen Person gegen die ganze Person)" (HEGEL, 2002, 42). É esta situação de indiferença, em que cada parte lança mão de uma atitude autoexcludente, que permite, segundo Hegel, a extrapolação da vingança do singular para corpos sociais múltiplos. Isto significa, sobretudo, que a contrapartida da defrontação da pessoa em sua totalidade com outra pessoa em sua totalidade é a contraposição de duas totalidades às quais cada qual pertence, o aprofundamento e diversificação das personalidades envolvidas na contenda. ${ }^{18}$ Sendo a honra a compaginação da existência individual formalmente instituída e dos caracteres que perfazem seu vínculo originário à existência social, a totalidade dos seus elementos físicos e sociais, a lesão da mesma é negação da eticidade natural. Trata-se da recuperação do vínculo interno entre o crime e a vida entendido antes como destino: a atitude individual autoexcludente, levada ao paroxismo de sua absolutização, colapsa em si mesma, já que com a honra o dano à pessoa é mostrado em sua vinculação à unidade da vida.

O risco de mútua aniquilação, de guerra (HEGEL, 2002, 46) e a insegurança generalizada do singular diante da possibilidade, intrínseca à própria liberdade singular, de ser lesado em sua pessoa, é a assimilação crítica ${ }^{19}$ da doutrina hobbesiana do estado de natureza. Hegel compreende este estado de insegurança não como um âmbito pré-ético da existência social, mas como a face negativa de uma existência social e ética pré-estatal que torna possível a "individualização", percebida agora em sua insuficiência sócio-integradora. Hegel concebe a liberdade pura, da qual também Hobbes parte, atribuindo a cada singular a capacidade potencialmente irrefreável de negar qualquer determinidade, até mesmo relações sociais originárias que lhe dão sustentação. Entretanto, para Hegel, as relações sociais engendradas pelo "paroxismo da autoexclusão", justamente por serem a forma exponencial da intersubjetividade originária, são relações estáveis de reconhecimento que rompem com o nexo exclusivamente limitativo do estado civil. Quanto à conexão entre o Naturrechtsaufsatz e o System der Sittlichkeit no tocante à formação do Einssein a partir do gradual rompimento pelos singulares de sua exterioridade mútua, em sua retroação sobre as formas pré-estatais de existência social, o capítulo sobre o crime (HONNETH, 1992, 42) representa justamente o processo pelo qual os indivíduos vão sendo progressivamente munidos 
das perspectivas sem as quais o Einssein das vontades singulares não pode ser formado de maneira imanente a elas, o que é a condição necessária às premissas não individualistas do conceito hegeliano de eticidade. No System der Sittlichkeit em particular, tal processo tem, como contrapartida social à expansão e ao descentramento da subjetividade, o amadurecimento de relações de reconhecimento recíproco que, ao nível do estofo intersubjetivo primário, não são capazes de abrigar plenamente as possibilidades desencadeadas pela liberdade negativa dos indivíduos. Com efeito, correspondente à passagem da pessoa jurídica à pessoa em sua totalidade está a intensificação da colaboração social e a consciência da própria dependência que tem um sujeito dos outros em aspectos imprescindíveis de sua plena individualização. “[...] nos sujeitos, no mesmo itinerário pelo qual eles chegam a uma maior autonomia, deve crescer, ao mesmo tempo, um saber acerca de sua dependência recíproca" (HONNETH, 1992, 43).

A exasperação do conflito jurídico numa luta por honra torna claro que, segundo a articulação entre a intersubjetividade excludente e a participativa, ${ }^{20}$ somente a demonstração da incompletude de formas estritamente jurídicas de existência social pode engendrar o teor intersubjetivo sobre o qual uma comunidade ética pode se formar. Não é por acaso, portanto, que Hegel sublinha que somente a constituição intersubjetiva ${ }^{21}$ do ser-um do indivíduo e da totalidade é capaz de preencher a condição de uma constituição do todo imanente às partes, o que justamente diferencia a compreensão hegeliana de comunidade de seu equivalente contratualista. $^{22}$

\section{2. "Luta" como crítica à liberdade negativa}

Seja do ponto de vista conceitual da progressão das figuras da consciência, ${ }^{23}$ seja sob a perspectiva do substrato histórico-filosófico correspondente às mesmas, ${ }^{24}$ já foi amplamente demonstrado que o movimento do reconhecimento tem uma importância sistemática para a Fenomenologia que excede sua tematização mais evidente nas partes introdutórias do capítulo "Consciência-de-si", intituladas "A verdade da certeza de si mesmo" e "Dependência e independência da consciência-de-si: dominação e escravidão", algumas das páginas hegelianas mais influentes para o pensamento filosófico do século $\mathrm{XX}^{25}$ e também mais comentadas.

Hegel mantém, em seus Esboços de Sistema anteriores à Fenomenologia, uma interessante Auseinandersetzung com o contratualismo. No Systementwurf 1803/1804, apesar de 
uma crítica explícita à noção kantiana de "contrato originário" (HEGEL, 1986a, 223), a ênfase do modelo de "luta por reconhecimento" reside muito mais no problema da "formação da consciência" (LIMA, 2011) e na verticalização de uma relação intersubjetiva horizontal (LIMA, 2007, 88 e seg) - talvez devido à ainda marcante influência da transposição da noção aristotélica

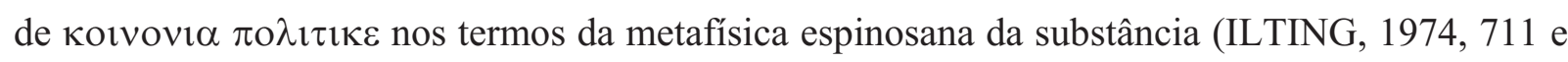
ss.). No Systementwurf 1805/1806 a crítica às premissas individualistas do contratualismo é mais clara (LIMA, 2010, 137 e ss.). Mostrei, recentemente, como uma compreensão consistente desta crítica demanda um apelo ao reiner Begriff des Anerkennens, enunciado na Fenomenologia (LIMA, 2010, 146).

Eis por que gostaria de concluir minha contribuição sustentando que a discussão sobre a luta posterior à Fenomenologia articula posições emblemáticas dentro da própria tradição contratualista. Trata-se, sobretudo, de compreender a filosofia política moderna, em sua sistematicidade, como explicando a passagem da liberdade negativa e ilimitada, cuja formulação mais célebre remonta a Hobbes, para uma concepção positiva da mesma, cuja enunciação como autodeterminação foi estabelecida por Rousseau e Kant. A apresentação dialética do contratualismo é também a revelação de sua insuficiência: ao conceber a liberdade positiva enquanto concretizada pelo ser-reconhecido, e não simplesmente como autodeterminação da vontade individual, Hegel está, na verdade, honrando uma intuição de juventude ${ }^{26}$ e, ao mesmo tempo, introduzindo a forma da base institucional: "A liberdade, configurada em efetividade de um mundo, recebe a forma da necessidade, cuja conexão substancial é o sistema das determinações da liberdade, e cuja conexão fenomênica é como poder (Macht), o serreconhecido, isto é, seu vigorar na consciência" (HEGEL, 1970, 8, 302). Tal resultado é da mais alta importância, principalmente se tivermos em vista o alcance da crítica hegeliana às concepções limitadas da liberdade individual através do conceito de vontade livre em-si-e-para-si (HEGEL, 1970, 7, §§7,21) (HONNETH, 2007, 77 e ss.).

O desdobramento da Fenomenologia sugere a compreensão do "ser-reconhecido" como télos do desenvolvimento do espírito prático, alcançado, ainda como um esboço, no início do capítulo "Espírito", mas, principalmente, na discussão sobre o "Mal e o seu Perdão" e sobre o "Saber Absoluto". ${ }^{27}$ Antes disso, a Fenomenologia enuncia a estrutura normativa da formação recíproca das identidades individuais e de sua autoconsciência universal (HEGEL, 1970, 3, 146). Separando o movimento do reconhecer da gênese imediata da eticidade, Hegel empreende, na 
abertura do capítulo "Consciência-de-si”, uma "espécie de pré-designação conceitual da estrutura do reconhecimento" (SIEP, 2000, 99).

Na Enciclopédia de 1830, Hegel volta a aproximar o movimento do reconhecer da noção de eticidade. Sendo a Fenomenologia um projeto "epistemológico" diferenciado, ${ }^{28}$ um "ceticismo que se completa a si mesmo" ocupado em mostrar a negatividade intrínseca e incontornável das figuras da consciência, o "puro conceito do reconhecer", a "verdade da certeza de si mesmo" (HEGEL, 1970, 3, 136), rapidamente é "rebaixado" à autoconsciência imediata, enredada na experiência dos percalços na persecução de sua plena realização, a começar pela incompletude de sua resolução da luta de vida e morte pela relação de dominação e servidão. É preciso esperar, na Fenomenologia, para experimentar a efetivação da estrutura normativa da intersubjetividade. ${ }^{29}$

Na Enciclopédia, embora a negatividade intrínseca de posições epistêmicas parciais esteja presente, ${ }^{30}$ sublinha-se a efetivação do reconhecimento recíproco num conceito concreto de liberdade individual. Hegel declara, nos $\S \S 33-42$ da "Doutrina da Consciência" dos Nürnberger Schriften (HEGEL, 1970, 4, 118), que, pelo movimento do reconhecimento da autoconsciência, realiza-se a passagem da "liberdade negativa" para a "liberdade positiva". Na Enciclopédia, o conceito de reconhecimento se liga mais facilmente à efetividade e concretude da liberdade em instituições sociais, constituindo, numa fundamentação regressiva da aparência de solipsismo excludente, a "substância da eticidade" (HEGEL, 1970, 8, 226). Se o ponto de partida do movimento - que é, ao mesmo tempo, a identidade que tem de se tornar efetiva mediante o processo - é a identidade abstrata do $\mathrm{Eu}=\mathrm{Eu}$, a verdade desta certeza abstrata de si é o " $\mathrm{Eu}$, que é Nós, Nós que é Eu” (HEGEL, 1970, 3, 144).

\section{Desejo e Luta}

O reconhecimento recíproco em sua estrutura normativa é o processo que leva do serpara-si imediato e formal, cuja expressão prática é o egoísmo do mero desejar, até o ser-para-si intersubjetivamente mediado, a liberdade como estar-junto-a-si-no-outro. A maneira como a luta encontra, na Fenomenologia, sua suspensão provisória com a relação de dominação é semelhante à Enciclopédia, onde, entretanto, ao invés de desaguar na deficiente autoconsciência estoica, fixada na sua singularidade abstrata, a relação de dominação é incorporada como passagem para a autoconsciência universal. Do ponto de vista de uma filosofia política, está menos remota a 
conexão entre o reconhecimento como estrutura normativa da autoconsciência e a luta como experiência.

No movimento de suspensão da contradição entre consciência e autoconsciência, entre o eu como identidade indiferenciada consigo e o objeto inessencial, o devir do outro como problema é a contrapartida da negação da singularidade pela satisfação que confere ao objeto o Charakter des Negativen (HEGEL, 1970, 8, 203/204, 424-429).

Há uma autoconsciência para uma autoconsciência: primeiro, imediatamente enquanto um Outro é para um Outro. Nele eu tenho a intuição de mim enquanto $\mathrm{Eu}$, mas também de um outro objeto sendo-aí imediatamente, como [um] Eu absolutamente autônomo em relação a mim (HEGEL, 1970, 8, 218).

Mas, tornando-se outro do outro e tendo um outro para o qual ela é outra também, a autoconsciência se torna um particular (HEGEL, 1970, 8, 218), conservando-se, no entanto, como pretensão de uma unidade indiferenciada consigo e que pretende, assim como o simples desejo, retornar a si a partir do outro. "Essa contradição dá o impulso para mostrar-se como livre $\mathrm{Si}$, e para ser aí para o Outro como tal: é o processo do reconhecimento" (HEGEL, 1970, 8, 218); pois, se elas têm "em comum a determinação da imediatez com a autoconsciência aprisionada no desejar" (HEGEL, 1970, 8, 218), são, enquanto o "Eu totalmente universal, absolutamente sem exceção, não interrompido por limite algum, a essência comum a todos os homens" (HEGEL, 1970, 8, 218). Por conseguinte, o ponto de partida da "autoconsciência que reconhece" é a ausência total de mediação, a confrontação (Kampf) entre duas autoconsciências na sua imediatez como identidades abstratas e mutuamente excludentes,

\footnotetext{
a enorme contradição de que [...] os dois Si que se referem aqui um ao outro constituem uma só identidade: por assim dizer, uma só luz e, no entanto, são ao mesmo tempo dois que persistem em uma rigidez e aspereza completas, um em relação ao outro, cada um como algo refletido sobre si, absolutamente distinto do Outro e impenetrável por ele" (HEGEL, 1970, 8, 218).
}

A contradição entre a universalidade de sua identidade abstrata e sua reversão em particularidades engendra, tal como na Fenomenologia, a luta, e o sentido da resolução da contradição é a mútua suspensão da imediatez, cuja radicalização faz com que cada autoconsciência somente possa refletir sobre si pela "aniquilação" da liberdade do outro. Mas o outro já se tornou autoconsciência, o ser-para-si no elemento de sua corporeidade, na qual "esta tem, como em seu signo e instrumento, seu próprio sentimento-de-si, assim como seu ser ethic@-Florianópolis, v. 11, n. 3, p.261 - 287. Dez. 2012. 
para outras e sua reação que a mediatiza com elas" (HEGEL, 1970, 8, 218). Como consequência, a relação de reconhecimento, cuja estrutura normativa foi previamente enunciada na Fenomenologia, é depois concebida, ainda que no sentido epistêmico continue a ser elevação da sua certeza de si à objetividade, como resultante da luta, como suspensão recíproca da imediatez, a qual significa aqui naturalidade (Natürlichkeit) e corporeidade (Leiblichkeit), o elemento responsável pela "rigidez e aspereza completas".

\section{Crítica ao contratualismo}

"Trata-se de uma luta" (HEGEL, 1970, 8, 218). O deparar-se imediato dos dois sujeitos ainda imersos no elemento não cultivado da naturalidade (Natürlichkeit), que os demove de sua pretensa independência e os engaja numa oposição de particulares, é o momento imediato do processo de reconhecimento. É um momento de tensão, pois a proximidade da identidade comum de particularidades contrasta com o caráter insondável das intenções que abriga sua possível autonomia, uma situação na qual nenhum dos dois tem a objetivação de sua certeza de si como ser racional livre.

Os homens devem, portanto, querer reencontrar-se um ao outro. Isso não pode acontecer, porém, enquanto eles estão presos em sua imediatez, em sua naturalidade: pois é ela justamente que os exclui um do outro, e os impede de ser como livres, um para o outro (HEGEL, 1970, 8, 219).

É o processo no qual tanto o eu quanto o outro suspendem suas respectivas imediatidades, permitindo a penetrabilidade recíproca de suas esferas de identidade como condição para a constituição recíproca destas identidades, para que cada um veja o outro como livre e possa assim também ver que é visto pelo outro como livre, isto é, ver a si mesmo como livre.

Somente assim se realiza a verdadeira liberdade: pois, já que ela consiste na identidade de mim com o outro, então eu só sou verdadeiramente livre quando o outro também é livre, e é reconhecido por mim como livre. (HEGEL, 1970, 8, 218).

A identificação da imediatez com a naturalidade (Natürlichkeit) de um indivíduo particular não cultivado retoma a herança hobbesiana, que Hegel traz desde Jena na sua 
compreensão do Naturzustand como condição de um conflito entre indivíduos exclusivamente autorreferentes.

\begin{abstract}
[...] a luta pelo reconhecimento na forma levada ao extremo, que foi indicada, só pode ter lugar no estado-de-natureza - em que os homens só existem como singulares: ao contrário, está longe da sociedade civil e do Estado, porque aqui mesmo o que constitui o resultado daquela luta, a saber: o ser-reconhecido, já está presente. (HEGEL, 1970, 8, 220).
\end{abstract}

Se o extremo de uma luta de vida e morte tem de ter sido abandonada na sociedade civil graças a sua liberação dos indivíduos para uma vida autorreferente regulada por sua identidade exterior, a sociedade civil repõe, em vista de seu nexo intersubjetivo de impenetrabilidade, o risco de ruptura do ser-reconhecido; e, sob esta perspectiva, a sociedade civil poderia ser compreendida, também intersubjetivamente, como "o sistema da eticidade perdida nos seus extremos" (HEGEL, 1970, 3, 339), o que conduz a explicitar os nexos reconstitutivos de uma intersubjetividade não excludente como condição para a passagem ao Estado (HEGEL, 1970, 7, $348)$.

Carências oriundas da mera naturalidade aproximam os homens de maneira exterior (HEGEL, 1970, 8, 218). Se o ser-reconhecido universal não se esgota nisto, pode-se ver aqui uma continuidade com o vínculo entre reconhecimento e eticidade, estabelecido nos Jenaer Systementwürfe (LIMA, 2010, 153). Hegel compreende a "sociedade civil", oriunda da "dissolução ética da família", como a reposição recorrente de uma identidade exterior que tem raízes na naturalidade, isto é, no "estado de natureza”. Enquanto resultante de um processo excludente de "individualização", a sociedade civil guarda em seu nexo intersubjetivo de mútua impenetrabilidade a possibilidade de ruptura do ser-reconhecido e de deflagração de "luta por reconhecimento".

A forma extrema da luta não esgota a compreensão do estado de natureza, pois neste se concebe não somente a morte como possível, mas o impedimento desta alternativa através da relação unilateral de reconhecimento como subterfúgio para a manutenção da vida, necessária para que a liberdade tenha um ser-aí, ainda que seja a liberdade de quem domina (HEGEL, 1970, $8,224)$. Portanto, o estado-de-natureza é o estágio em geral de um não reconhecimento, quer tenha sido paralisado em sua iminência, quer tenha sido instituído de maneira assimétrica. $\mathrm{O}$ estado-de-natureza guarda em si o rol de possibilidades incluídas no estágio em que os seres 
humanos convivem apenas como singulares excludentes, seres racionais que se supõem absolutamente livres, mas que, mergulhados no egoísmo e no solipsismo da utilização da sua exterioridade em geral como meio para a realização de fins particulares, deparam-se uns aos outros como particularidades "impenetráveis".

Com efeito, explorando o tema não desenvolvido nos capítulos XIII e XIV do Leviatã, Hegel relaciona a "condição natural", a não-eticidade do homem explicitamente ao não-serreconhecido pelo outro, isto é, compreende o estado de natureza como estágio "em que os indivíduos, sejam o que forem, e façam o que fizerem, querem extorquir-se reconhecimento." (HEGEL, 1970, 8, 222) O reconhecimento recíproco é, neste contexto, condição para a passagem deste estágio, em que todo mútuo respeitar é condicionado pelo empenho da "subjetividade vazia" (HEGEL, 1970, 8, 222), para o estágio de uma vida ética e, com isso, condição da própria universalidade e objetividade do respeito recíproco, do sentimento mútuo de dignidade e dos laços de solidariedade, não apenas numa escala interpessoal, mas coletiva - ou, como diz Hegel, da "honra" em seu "conteúdo substancial, universal, objetivo" (HEGEL, 1970, 8, 220).

Na obra de 1830, portanto, a luta é, aparentemente, assimilada ao vínculo estabelecido em Jena entre reconhecimento e eticidade, deixando-se integrar no projeto de correção críticoespeculativa do jusnaturalismo contratualista, visível no argumento, levado a termo nas Grundlinien, de um quadro institucional, cuja forma consciente é o ser-reconhecido e que condiciona o individualismo pressuposto pelo contratualismo hobbesiano.

Até mesmo a resolução parcial da luta na "dialética entre senhor e escravo" é introduzida, curiosamente, no contexto de uma passagem do Naturzustand para a Sittlichkeit, a identidade concreta dos indivíduos em sua diferença, "passagem do estado da consciência-de-si submersa no desejo e na singularidade ao estado da consciência-de-si universal" (HEGEL, 1970, 8, 222). Deste modo, o processo de reconhecimento é introduzido por Hegel no quadro de um argumento próprio à teoria do contrato, de maneira que revela as condições objetivas e subjetivas de possibilidade do estado: instituições na forma do ser-reconhecido.

O que domina no Estado são o espírito do povo, os costumes, a lei. Ali o homem é reconhecido e tratado como ser racional, como livre, como pessoa; e de seu lado, o singular faz-se digno desse reconhecimento porque, com a superação da naturalidade de sua consciência-de-si, ele obedece a um universal, à vontade essente em si e para si, à lei: portanto, comporta-se para com os outros de uma maneira universalmente válida, 
reconhece-os como ele mesmo quer valer: como livre, como pessoa (HEGEL, 1970, $8,220 / 221)$.

\section{O que se pode depreender da diversidade de abordagens?}

Pertence à essência do reconhecimento a mútua confirmação da identidade a si fundada no recíproco "deixar o outro ir livremente". ${ }^{31}$ Sem este elemento, a identidade concreta do "nós", que deve ser alcançada como condição da liberdade da consciência-de-si, não passaria daquela identidade abstrata que se afirma pela negação da diferença. A renúncia à dominação do outro, que é crucial para a estrutura normativa do reconhecimento mostra também que a identidade individual concreta é resultado de um processo que não está totalmente sob o controle do sujeito autocrático. A perda de si mesmo na constatação de que a universalidade abstrata deu lugar a uma oposição entre particulares foi superada, no contexto da estrutura normativa, sem a eliminação do outro, mas com sua coparticipação num sistema de mútua liberação, um aspecto "ideal" do movimento de reconhecimento que pode se concretizar em diversas formas: como no amor, na amizade, nos costumes de um povo, no perdão, na reconciliação ${ }^{32}$ e, talvez também na ampliação conflituosa desta identidade. Embora este âmbito "formal" não diga nada a respeito de como a equivalência entre ser-para-outro e ser-para-si é de fato trazida à efetividade, ao evidenciar o plano da experiência onde esta relação tem de ser produzida, ele reivindica não ser simplesmente formal. ${ }^{33}$

O malogro da tentativa de reconhecimento na luta e na dominação atesta que, no contexto da Fenomenologia, o télos do movimento deve ser procurado em figuras posteriores da experiência, e isso, como se viu, no sentido de uma unidade que se sabe espírito dos singulares, como no Systementwurf 1803/04, mas não especificamente como vontade universal abstrata que sabe a si mesma na imediatez da reciprocidade entre direitos e deveres no estado jurídico-civil, como em 1805/06. No privilégio quase epistêmico da luta por reconhecimento - presente na Fenomenologia, mas não nos Systementwürfe - pelo qual se escamoteia a emergência dos indivíduos excludentes e conflitantes a partir de sua formação prévia em redes de uma intersubjetividade inclusiva, reside uma peculiaridade. Em textos anteriores, a deflagração da luta se encontra na emergência de sujeitos individualizados pela sua preexistência intersubjetiva na família e, mais especificamente, na tomada de posse excludente, como 1805/06, na lesão à posse 
alheia, como no System der Sittlichkeit, e na necessidade de mútua lesão das pretensões conflitantes à totalidade, como em 1803/04.

Já nos escritos posteriores à Fenomenologia, com forte ênfase ético-política, a luta é paulatinamente inserida como parte do processo - por exemplo, nos Nürnberger Schriften - até que, na Enciclopédia de 1830, ela se torna tão vital para o movimento da "consciência-de-si que reconhece" que passa a ser o elemento genético do resultado do movimento: a consciência-de-si universal.

Assim, na teoria do reconhecimento apresentada na Enciclopédia, a consciência-de-si completa em si mesma a passagem da liberdade negativa para a positiva. Na Fenomenologia, a partir da estabilização da luta na dominação surge uma nova figura da consciência, a consciência estoica, a qual, dando continuidade à consciência servil, localiza-se acima daquela relação de dominação e conta ainda com uma aproximação, permitida por Hegel, de seu estágio peculiar de autoconsciência espiritual com o mundo sócio-espiritual: ela é interpretada por Hegel, em sua "independência carente-de-espírito", como "princípio do estado de direito" (HEGEL, 1970, 3, $355)$.

É possível que Hegel tenha se impressionado com a diferença de abordagens. Talvez um dos mais significativos indícios disto esteja na "Doutrina-da-Consciência para a classe intermediária" dos Nürnberger Schriften (1808/09), a qual fora pensada ainda, como declara Hegel, como introdução à filosofia (HEGEL, 4, 73). Nesta obra, que, segundo a compreensão sistemática, se aproxima mais da Enciclopédia do que da Fenomenologia, Hegel apresenta, como resultado do processo de reconhecimento, não mais a consciência-de-si estoica, mas a "consciência-de-si universal".

\footnotetext{
A consciência-de-si universal, sendo espírito vivo, universalidade que é, ao mesmo tempo, individualidade, tendo renunciado à sua particularidade e sabendo a si mesma sendo em-si e, portanto, como idêntica aos outros, é reconhecida e reconhece (HEGEL, $1970,4,84){ }^{34}$
}

Caberia indagar, numa próxima oportunidade, se na Fenomenologia, que toma a consciência como capacidade de autocorreção fundada nesta autorreflexividade, haveria outras dimensões imprescindíveis do conceito de Luta (HEGEL, 1970, 3, 399). 


\title{
Notas
}

\begin{abstract}
${ }^{1}$ Interessante aqui é recorrer, do ponto de vista da epistemologia da crítica social, à "integração hegeliana", proposta por Honneth para o programa de uma crítica do poder. "Foucault e Habermas, em contrapartida, alcançam o âmbito fenomênico do social (das Soziale), o qual permaneceu estranho à tradição da teoria crítica da sociedade, a partir de lados extremamente contrapostos, no que tange à teoria da ação: Foucault no paradigma da "luta" (Kampf), Habermas naquele da "compreensão" (Verständigung). A partir de uma análise das dificuldades às quais conduzem, em cada caso e num nível diferenciado de reflexão, estas propostas teóricas, devem resultar implicitamente as linhas que uma "crítica do poder" teria hoje de trilhar" (HONNETH, 1989, 8).
\end{abstract}

${ }^{2}$ Esta tese de leitura Ilting pretende confirmar, sobretudo, apelando à estrutura tripartite de System der Sittlichkeit (ILTING, 1974, 711).

3 À incontestável influência de Hobbes nas concepções hegelianas em Jena e que se vinculam à luta por reconhecimento já se aludiu de maneira bastante consistente (SIEP, 1974, 155-209).

${ }^{4}$ Ilting compreende o projeto hegeliano traçado em Jena como uma tentativa de unificar política de Aristóteles com o direito natural tal como ele é compreendido pelo pensamento político que se inicia com Maquiavel, passa por Hobbes e chega até Espinosa. Ilting sustenta que o programa de um "sistema da eticidade", delineado no Naturrechtsaufsatz e levado a termo, graças ao alinhamento de Hegel à Potenzenmethode de Schelling, no System der Sittlichkeit, caracteriza-se, sobretudo, por uma equiparação da doutrina espinosana da substância infinita, à qual Hegel adere imediatamente depois da Seinsmetaphysik do período de Frankfurt graças à influência do projeto schellingniano de mediação entre Kant e Espinosa, com a doutrina aristotélica da comunidade política. Esta equiparação permite a Hegel fundamentar a primazia do positivo ou do povo no fato de que este, enquanto substância que se diferencia, é primordial em relação ao negativo ou ao indivíduo (ILTING, 1974).

${ }^{5}$ Para Ilting, a peculiaridade de uma filosofia política como a hegeliana, concebida como tentativa de integrar no quadro geral da primazia da pólis motivos oriundos do direito natural moderno, está justamente em ter conferido um novo significado à temática moderna da luta pela afirmação individual de prerrogativas: a imposição social do poder constituído como estado não visa somente à afirmação pragmática da "verdade social" como solução para a ameaça ubíqua de desintegração graças à exacerbação do princípio do egoísmo, mas, sobretudo, a produzir, para os próprios combatentes, a verdade e a efetividade da pertença de ambos ao povo. Nisto consiste a possibilidade de absorção do conflito social a uma compreensão da comunidade política que se considera como correção do individualismo moderno e de sua redução da política ao agregado de átomos subsistentes por si, isto é, como capaz de compreender o nexo político da comunidade humana como algo essencialmente inclusivo e "solidário" (ILTING, 1974).

${ }^{6}$ Habermas considera que a experiência da proveniência contextual é um exemplo de como "Hegel opera com a força de reconciliação de uma razão que não se deixa deduzir imediatamente da subjetividade" (HABERMAS, 2002, 41) e "não pode ser deduzida, como as leis da razão prática, a partir do conceito da subjetividade por meio do conceito de vontade autônoma" (HABERMAS, 2002, 43). Eis aí a perene inspiração hegeliana em Habermas: "essa mudança de pensamento poderia ter dado o impulso para recuperar e remodelar, em termos de uma teoria da comunicação, o conceito de reflexão da razão desenvolvida na filosofia do sujeito. Hegel não trilhou este caminho" (HABERMAS, 2002, 45).

${ }^{7}$ Hegel amplia, com seu conceito de positividade, a noção kantiana de heteronomia e passa a compreender, tanto ela quanto a autonomia moral da vontade, como formas de uma positividade cujo denominador comum é a "forma legal" da moral e do direito enquanto tal, na medida em que a lei supõe uma contraposição entre o particular e o universal vazio da obrigação. "Lei é uma relação pensada dos objetos uns aos outros [...] Uma relação pensada é firme e permanente, sem espírito, um jugo (Joch), um encadeamento (Zusammenkettung), uma dominação e escravidão atividade e sofrimento (Tätigkeit und Leiden), determinar e ser-determinado" (HEGEL, 1970, 1, 308/309). Ao procurar solucionar a dominação e a cisão produzidas pela racionalidade subjetiva, abstrata e instrumental, através da força reconciliadora de uma racionalidade pressuposta como originária em relação aos processos de individualização, a qual tem uma natureza razão intersubjetiva, contextual e comunitariamente compartilhada, Hegel não somente

ethic@-Florianópolis, v. 11,n.3,p.261-287. Dez.2012. 
denuncia seu fascínio pelos passados idealizados do cristianismo primitivo e da pólis clássica enquanto totalidades éticas originárias, mas não produzidas modernamente (HABERMAS, 2002, 44); mais do que isso, a dominação é "reconduzida [...] a uma subjetividade alienada, afastada da vida em comum. E a repressão resultante origina-se da perturbação de um equilíbrio intersubjetivo, e não da submissão de um sujeito que se tornou objeto" (HABERMAS, 2002, 44).

${ }^{8}$ Trata-se de uma tese de vasto alcance, antecipada, segundo Habermas, por Hegel. "todos os fenômenos históricos têm maior ou menor participação na estrutura dialética das relações de reconhecimento recíproco, nas quais pessoas são individualizadas pela socialização (Vergesellschaftung)" (HABERMAS, 2004). Estabelecida a conexão entre a normatividade e os processos de socialização e individualização (HABERMAS, 1974, 790/791), ele a aprofunda no sentido da relação, desenvolvida pela ética do discurso, entre a eticidade e o ponto de vista moral, ao investigar como pode ser compensada a descontextualização da moral universalista no sentido de uma vinculação da motivação racional com as atitudes empíricas eficazes, ancoradas em uma socialização individualizante (HABERMAS, 1991, 16-37). Finalmente, a vulnerabilidade da individualização pela socialização é retomada sob a perspectiva da complementaridade entre moral e direito (HABERMAS, 1997, 565).

${ }^{9}$ Para Hegel, o crime não pode ser visto simplesmente como uma transgressão da lei, mas antes como uma violação da vida em sua unicidade, dilaceramento da mesma. "A enganação do crime, que crê destruir vida estranha e ampliar a si mesmo com isso, se dissolve quando o espírito deixado para trás da vida lesada entra em cena contra o mesmo" (HEGEL, 1970, 1, 342).

${ }^{10}$ Para Hegel, a pena surge como o universal abstrato da lei totalmente apartado do particular, isto é, o universal do dever desligado da ação individual (HEGEL, 1970, 1, 340).

${ }^{11}$ É neste horizonte temático, que antecipa, ainda no registro do conceito de vida e ser da Vereinigungsphilosophie, o poder nadificante da concepção de "eticidade absoluta" no Naturrechtsaufsatz, que Hegel compreende a vida como âmbito anterior e originário do qual a lei surge como "vida incompleta", universal contraposto, incapaz de reconciliar a vida em sua beleza originária. "Mas, na pena como destino, a lei é mais tardia do que a vida e se encontra mais profundamente do que esta. Ela é apenas a lacuna da mesma, a vida falha (das mangelnde Leben) enquanto poder" (HEGEL, 1970, 1, 343/344).

12 “o destino não é nada estranho [...] é a consciência de si mesmo, mas [consciência de si mesmo] enquanto de um inimigo. $\mathrm{O}$ todo pode restabelecer dentro de si a amizade, ele pode retornar à sua vida pura através do amor: assim se torna sua consciência novamente crença em si mesmo, a intuição de si mesmo se tornou uma outra e o destino está reconciliado" (HEGEL, 1970, 1, 346).

${ }^{13}$ Para Habermas, a "causalidade do destino", a força de restabelecimento de uma relação ética desencadeada pela complementaridade da comunicação não coagida e da satisfação recíproca de interesses, é o exemplo originário da "dialética da relação ética", da Kampf um Anerkennung. Habermas a interpreta como experiência, "na relação dialógica do conhecer-se-no-outro, do fundamento comum de sua existência” (HABERMAS, 1974, 791/792).

${ }^{14}$ Fischbach atribui a Hegel a conexão da teoria do reconhecimento enquanto "teoria das condições intersubjetivas transcendentais da subjetividade", elaborada por Fichte, com a perspectiva da "luta por reconhecimento", isto é, da perspectiva da consecução deste reconhecimento a partir de árduo embate no plano de ação dos indivíduos. Habermas e Honneth reproduziriam este embate num registro "pós-metafísico" de discussão (FISCHBACH, 1999, 123). A "pragmática linguística universal" investigaria as normas imanentes da atividade comunicacional orientada ao entendimento mútuo. Para Honneth, embora seja a normatividade imanente do agir comunicacional que funda a possibilidade de se adotar um ponto de vista crítico sobre o que cria empecilhos à plena efetivação da interação, somente a perspectiva do "não reconhecimento" e do "desrespeito" que embasa o ponto de vista da crítica social, a autocompreensão dos sujeitos como parceiros na interação linguisticamente mediatizada. Eis por que o modelo de Hegel passa a servir, como conexão do desenvolvimento conflituoso dos níveis sócio-institucionais de intersubjetividade com a experiência moral da não efetivação do teor normativo do interagir social, com a "dinâmica social do desrespeito (Missachtung)", enquanto reorientação da "teoria crítica" (HONNETH, 2000). Contudo, na interpretação fornecida por Habermas para a discussão sobre a "causalidade do destino" mostra que a virada linguística na teoria crítica vem inspirada por uma experiência da negatividade da cisão na eticidade.

ethic@-Florianópolis, v. 11,n.3,p.261-287. Dez.2012. 
${ }^{15}$ Uma interpretação favorecida pela descoberta de que se trata de uma crítica sistemática da teoria fichteana do direito natural (HEGEL, 2002,). O System der Sittlichkeit representaria este interessante híbrido na trajetória do desenvolvimento de Hegel, pelo qual a correção do individualismo e atomismo próprios ao direito natural moderno, através do recurso às concepções aristotélicas a respeito da "anterioridade da pólis", encontra a possibilidade, suscitada pela teoria fichteana da intersubjetividade, de apresentar o desdobramento da totalidade ética na forma de uma sobreposição de paradigmas de relação intersubjetiva que são conservados na efetivação da liberdade como comunidade. Vejo nesta integração de Fichte e Aristóteles a gênese do plano definitivo de desdobramento da eticidade, em sua conexão específica com o direito.

${ }^{16}$ Que o capítulo sobre o crime representa o "paroxismo da exclusão", deve-se ao vínculo inextricável entre liberdade pura e pura negatividade. Viu-se acima que a gênese da pessoa já trouxera o tema da liberdade negativa à tona. Esta liberdade de poder abstrair de tudo é agora levada ao seu momento radical pela negação da própria vida e, portanto, dos vínculos éticos naturalmente estabelecidos (SCHNÄDELBACH, 2000, 94/95)

${ }^{17}$ Se e em que medida esta exigência possui um sustentáculo nas determinações metodológicas do texto de Hegel, como defende Kimmerle, deixamos aqui em aberto, já que nos interessa, sobretudo, o teor social da tipologia da exclusão criminosa (KIMMERLE, 1970, 235).

18 "Mas a uma luta por "honra" somente se pode manifestamente chegar, porque a possibilidade para uma tal autorrelação afirmativa é dependente, por sua vez, do reconhecimento confirmador por outros sujeitos. Um indivíduo somente é capaz de uma completa identificação consigo mesmo, na medida em que ele encontra, em suas peculiaridades e propriedades, também através de seus parceiros de interação, assentimento e apoio." (HONNETH, 1992, 41)

${ }^{19}$ Apesar de Hegel somente introduzir, no System der Sittlichkeit, o conceito de luta no segundo momento do desdobramento da atitude criminosa, Honneth acredita que o texto esteja amplamente influenciado por este conceito, o que se deixa perceber, sobretudo na difícil aglutinação que, segundo ele, é feita por Hegel da filosofia política de Aristóteles, da teoria do reconhecimento de Fichte e a doutrina do direito natural de Hobbes (SCHNÄDELBACH, 2000, 98).

${ }^{20}$ Há, de fato, como identifica Honneth, uma peculiaridade no System der Sittlichkeit: a luta não é um estágio intermediário entre as formas de reconhecimento, mas, ao contrário, diferentes tipos de luta, associados a estes estágios, são inseridos em um único capítulo (HONNETH, 1992, 35 e 36). Atribuo esta peculiaridade à compreensão do arcabouço intersubjetivo da existência social dos indivíduos como uma articulação entre uma forma inclusiva e uma excludente de relação intersubjetiva.

${ }^{21}$ A fórmula da intuição de si mesmo no outro significa "uma forma da relação recíproca entre os sujeitos que é superior à forma meramente cognitiva”, a qual caracteriza para ele o reconhecimento jurídico. Para Honneth, os elementos solidários contidos na intuição de si no outro "devem fornecer manifestamente a base comunicativa sobre a qual os indivíduos isolados uns dos outros pela relação de direito podem, mais uma vez, se encontrar no quadro mais abrangente de uma comunidade ética" (HONNETH, 1992, 44).

${ }^{22}$ Hegel desenvolve esta relação na forma de uma contraposição entre a comunidade enquanto totalidade dialética e a sociedade enquanto "agregado" concebido na base de um atomismo social (HEGEL, 2002, 49).

${ }^{23}$ Para Siep, em momentos decisivos do processo de formação da consciência em direção à autoconsciência universal na sua forma espiritual, a estrutura do reconhecimento recíproco aparece como critério normativo deste processo gradual, principalmente na passagem da razão prática para o espírito e na conclusão das três figuras principais do espírito, somente podem ser compreendidos como momentos de um reconhecimento mútuo entre singular e pelo universal (SIEP, 1976, 99).

${ }^{24}$ Especialmente nítida se torna a relação entre as figuras da consciência em sua trajetória de formação na Fenomenologia e o substrato histórico-filosófico que corresponde a elas com o sensacional trabalho de Falke (FALKE, 1996).

ethic@-Florianópolis, v. 11, n. 3, p.261 - 287. Dez. 2012. 


\begin{abstract}
${ }^{25}$ Na recepção da Fenomenologia e do desenvolvimento das figuras iniciais da "Consciência-de-si" - como desejo, a luta por reconhecimento, a relação entre senhor e escravo - feita no século XX, parece ter sido especialmente atraente a idéia de uma compreensão das representações da realidade em seu vínculo com a história social. Dentre estas recepções, cumpre citar ao menos a interpretação marxista de Lukàcs e a existencialista de Kojève.
\end{abstract}

26 "a mais elevada comunidade é a mais elevada liberdade, tanto segundo o poder, quanto segundo a execução" (HEGEL, 1970, 2, 82).

${ }^{27}$ Sobre esta interpretação do "movimento do reconhecimento" como télos do "programa de filosofia prática" contido na trajetória da Fenomenologia, três trabalhos me parecem ser de suma importância: (WILLIAMS, 1992) e (SIEP, 1976, 1998).

${ }^{28}$ Pode-se diferenciar, na Fenomenologia, por um lado, a intenção "conceitual", explicitada desde a Differenzschrift, de construir o absoluto para a consciência, uma influência da formulação fichteana da separação autoconsciência pura e consciência empírica. Por outro lado, a intenção "histórico-filosófica" de restituir à filosofia o absoluto, anunciada em Glauben und Wissen. Neste sentido, a Fenomenologia aparece como mediação entre a crítica kantiana e a filosofia da identidade de Fichte e Schelling (FALKE, 1996, parte A).

${ }^{29}$ Ver: (HEGEL, 1970, 3, 291 e ss.). Mais à frente: "reconhecimento recíproco que é espírito absoluto" (HEGEL, 1970, 3, 408 e 471).

${ }^{30}$ Um exemplo eloquente desta presença da crítica especulativa de outras compreensões filosóficas é dado, sem dúvida, no Vorbegriff (§§ 19-83) da Ciência da Lógica na Enciclopédia, onde Hegel faz anteceder à consecução do próprio ponto de vista de sua lógica especulativa uma crítica das "posições do pensamento com respeito à objetividade metafísica" ( $\$ \S 26-78)$.

${ }^{31}$ A partir disso, pode-se questionar certa unilateralidade na interpretação do conceito hegeliano de reconhecimento como a que pretende Kojève ao reduzir este movimento à consideração da relação de dominação e escravidão (WILLIAMS, 1997).

${ }^{32}$ Em seu trabalho principal, Siep desvendou a função muitas vezes recôndita, mas de fato imprescindível, da "estrutura" do processo de reconhecimento para o desenvolvimento das figuras da Fenomenologia, e isto não somente no que diz respeito propriamente à relação intersubjetiva simétrica (entre eu e outro eu), mas, sobretudo, sua emergência nas figuras da consciência e do espírito, que se pode caracterizar como relações entre a consciência individual e universal (SIEP, 1976).

${ }^{33}$ Ao reduzir a intersubjetividade à relação de dominação do escravo pelo senhor, Kojève demonstra não atentar à distinção clara entre a estrutura normativa do conceito de reconhecimento e a experiência da consciência. Em primeiro lugar, Kojève parece não considerar a "reversão da figura da consciência servil ou infeliz, alienada de si mesma, do mundo e de Deus, na discussão de Hegel acerca da razão como uma estrutura dinâmica e objetiva 'nomundo'." (WILLIAMS, 1997, 67). Além disso, Kojève parece desconhecer o reconhecimento recíproco constitutivo da família considerado na interpretação de Antígona (HEGEL, 1970, 3, 274-275 e 325-326). Finalmente, também não considera a relação afirmativa ao outro no reconhecimento que tem lugar no perdão, e mesmo o "reconhecimento recíproco que é espírito absoluto" (HEGEL, 1970, 3, 408 e 471).

34 A intersubjetividade da consciência-de-si universal que se tornou consciente de si mesma é ainda mais exemplarmente formulada na "Doutrina-da-Consciência" de 1809: "A consciência-de-si universal é a intuição de si mesmo como um Si não particular e diferente dos outros, mas de um Si universal e em-si essente. Assim ele reconhece em si a si mesmo e as outras consciências-de-si e é reconhecido por elas." (HEGEL, 1970, 4, 120/121). 


\section{Referências Bibliográficas}

BRANDOM, R 2002. Tales of the Mighty Dead: Historical Essays in the Metaphysics of Intentionality. Cambridge: Harvard University Press.

FALKE, G. 1996. Begriffene Geschichte. Das historische Substrat und die systematische Anordnung der Bewußtseinsgestalten in Hegels 'Phänomenologie des Geistes'. Interpretation und Kommentar. Berlin: Lukas-Verlag.

HABERMAS, J. 1974. “Arbeit und Interaktion. Bemerkungen zu Hegels Jenenser 'Philosophie des Geites””. In: GÖHLER, G. Frühe politische Systeme. Frankfurt am Main: Ullstein.

. 1988. "Individuierung durch Vergesellschaftung" in: Nachmetaphysisches Denken, Frankfurt am Main: Suhrkamp.

. 1999. "Wege der Detranzendentalisierung: Von Kant zu Hegel und züruck" in: Wahrheit und Rechtfertigung: philosophische Aufsätze, Frankfurt am Main: Suhrkamp. .2001. A Constelação Pós-nacional: Ensaios Políticos. Littera Mundi: São Paulo. . 2004. 2004 Verdade e Justificação: ensaios filosóficos. São Paulo: Loyola.

HEGEL, G.W.F. 1970. Werke in 20 Bände. Frankfurt am Main : Suhrkamp.

. 1986a. Jenaer Systementwürfe I. Hamburg: Felix Meiner.

. 1986b. Jenaer Systementwürfe III. Hamburg: Felix Meiner.

Meiner.

2002. System der Sittlichkeit [Critik der Fichteschen Naturrechts], Hamburg: Felix

HONNETH, A. 1992. Kampf um Anerkennung. Zur moralischen Grammatik sozialer Konflikte. Frankfurt am Main: Suhrkamp.

. 2000. "Zwischen Aristoteles und Kant: Skizze einer Moral der Anerkennung" in: HONNETH, A. Das Andere der Gerechtigkeit: Aufsätze zur praktischen Philosophie. Frankfurt am Main: Suhrkamp.

. 2004. "Gerechtigkeit und Kommunikative Freiheit: Überlegungen im Anschluss an

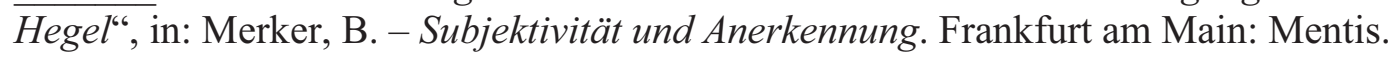

1994 Kontexte der Gerechtigkeit: politische Philosophie jenseits von Liberalismus und Kommunitarismus. Frankfurt am Main: Suhrkamp. 
.2001. Leiden an Unbestimmtheit. Berlin: Reclam.

ILTING, K. 1974. Hegels Auseinandersetzung mit der aristotelischen Politik. In: GÖHLER, G. Frühe politische Systeme. Frankfurt am Main: Ullstein.

LIMA, E. C. 2006. Direito e Intersubjetividade: eticidade moderna em Hegel e o conceito fichteano de reconhecimento. Campinas. 293 p. Tese de Doutorado em Filosofia, UNICAMP.

. 2007. Gênese do Espírito Ético na Filosofia do Espírito de Jena. Cadernos de Ética e Filosofia Política (USP), v. 10, p. 79-102.

2010. O Conceito Hegeliano de Direito na Filosofia do Espírito de 1805/1806. Veritas (PUCRS). v. 55, n. 3, p.130-157.

. 2011. Linguagem e Formação na Teoria da Consciência do Jovem Hegel. Trans/Form/Ação (Unesp), v. 34, n.1, p. 67-86.

MEIST, K. 1980 Hegels Systemkonzeption in der frühen Jenaerzeit, In: DÜSING, K. Hegel in Jena. Bonn: Bouvier.

.2002. Einleitung. In: G.W.F Hegel, System der Sittlichkeit [Critik des Fichteschen Naturrechts]. Hamburg: Felix Meiner.

RIEDEL, M. 1969. "Hegels Kritik des Naturrechts". In: RIEDEL, M. Studien zu Hegels Rechtsphilosophie. Frankfurt am Main: Suhrkamp.

. 1974. "Die Rezeption der Nationalökonomie". In: GÖHLER, G. Frühe politische Systeme. Frankfurt am Main: Ullstein.

ROTH, K 2002. Abstraktes Recht und Sittlichkeit in Hegels Jenaer Systementwürfen, In:

HENKEL, M. Staat, Politik und Recht beim frühen Hegel, Berlin: BWV,11-37.

SCHNÄDELBACH, H. 2000. Hegels praktische Philosophie: Ein Kommentar der Texte in der Reihenfolge ihrer Entstehung. Frankfurt am Main: Suhrkamp.

SIEP, L. 1979. Anerkennung als Prinzip der praktischen Philosophie. Freiburg/München: Alber.

. 1992. Der Freiheitsbegriff der praktischen Philosophie Hegels in Jena, in: SIEP, L. Praktische Philosophie im deutschen Idealismus. Frankfurt am Main: Suhrkamp.

. 1998. Die Bewegung des Anerkennens in der Phänomenologie des Geistes. In: KÖHLER, D. G.W.F Hegel, Phänomenologie des Geistes, Berlin: Akademische Verlag.

. 2000. Der Weg der Phänomenologie des Geistes. Ein einführender Kommentar zu

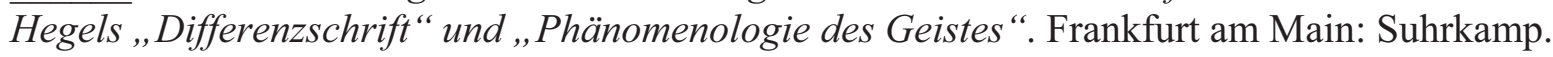


. 2004. "Selbstverwirklichung, Anerkennung und politische Existenz. Zur Aktualität der politischen Philosophie Hegels", in: Gerechtigkeit und Politik. Philosophische Perspektiven, Schmücker, R. Berlin: Akademie Verlag.

WILDT, A. 1983. Autonomie und Anerkennung. Hegels Moralitätskritik im Lichte seiner FichteRezeption. Stuttgart: Klett-Cotta.

WILLIAMS, R 1992. Recognition: Hegel and Fichte on the Other. Albany: University of New York Press. .1997. Hegel's Ethics of Recognition. Los Angeles: University of California Press.

. 2001. Beyond liberalism and communitarianism: studies in Hegel's Philosophy of right. New York: Albany. 